\title{
Combining phospholipases and a liquid lipase for one-step biodiesel production using crude oils
}

\author{
Silvia Cesarini ${ }^{1,3}$, Rune Falkenberg Haller ${ }^{2}$, Pilar Diaz $^{1 *}$ and Per Munk Nielsen ${ }^{3}$
}

\begin{abstract}
Background: Enzymatic biodiesel is becoming an increasingly popular topic in bioenergy literature because of its potential to overcome the problems posed by chemical processes. However, the high cost of the enzymatic process still remains the main drawback for its industrial application, mostly because of the high price of refined oils. Unfortunately, low cost substrates, such as crude soybean oil, often release a product that hardly accomplishes the final required biodiesel specifications and need an additional pretreatment for gums removal. In order to reduce costs and to make the enzymatic process more efficient, we developed an innovative system for enzymatic biodiesel production involving a combination of a lipase and two phospholipases. This allows performing the enzymatic degumming and transesterification in a single step, using crude soybean oil as feedstock, and converting part of the phospholipids into biodiesel. Since the two processes have never been studied together, an accurate analysis of the different reaction components and conditions was carried out.

Results: Crude soybean oil, used as low cost feedstock, is characterized by a high content of phospholipids (900 ppm of phosphorus). However, after the combined activity of different phospholipases and liquid lipase Callera Trans $L$, a complete transformation into fatty acid methyl esters (FAMEs $>95 \%$ ) and a good reduction of phosphorus ( $\mathrm{P}<5 \mathrm{ppm}$ ) was achieved. The combination of enzymes allowed avoidance of the acid treatment required for gums removal, the consequent caustic neutralization, and the high temperature commonly used in degumming systems, making the overall process more eco-friendly and with higher yield. Once the conditions were established, the process was also tested with different vegetable oils with variable phosphorus contents.

Conclusions: Use of liquid lipase Callera Trans $L$ in biodiesel production can provide numerous and sustainable benefits. Besides reducing the costs derived from enzyme immobilization, the lipase can be used in combination with other enzymes such as phospholipases for gums removal, thus allowing the use of much cheaper, non-refined oils. The possibility to perform degumming and transesterification in a single tank involves a great efficiency increase in the new era of enzymatic biodiesel production at industrial scale.
\end{abstract}

Keywords: Enzymatic biodiesel, Liquid lipase, Crude oils, Phospholipases

\section{Background}

Lipase-catalyzed biodiesel production is an intensive area of research because of its potential to generate ecofriendly fuel. Indeed, employment of lipases as biocatalysts in the transesterification of triacylglycerides allows mild reaction conditions and easy recovery of glycerol, without need for further purification or chemical waste production. In addition, the enzymatic process tolerates the common water content of oil and increases the

\footnotetext{
*Correspondence: pdiaz@ub.edu

'Department of Microbiology, University of Barcelona, Avenida Diagonal 643, Barcelona 08028, Spain

Full list of author information is available at the end of the article
}

biodiesel yield, avoiding the typical soap formation due to alkaline transesterification [1]. Various lipases from different sources, generally in their immobilized form, have been investigated for transesterification using several substrates [2]. To date, high lipase activity and stability, with very good conversion rates in short reaction times, have been reported [3-6]. However, the high costs of enzyme immobilization remain a major drawback for lipase-catalyzed biodiesel production. The immobilization process and the supports used make the enzymatic transesterification economically not competitive against the chemical process [3,7]. According to Ghaly et al. (2010), the cost of the enzyme makes up to $90 \%$ of the total cost of the 
enzymatic process [3]. Moreover, lipase inhibition due to binding of the released glycerol to the supports has been reported [8]. In order to make the process more competitive and sustainable, the possibility of using soluble, nonimmobilized lipases in biodiesel production is being investigated nowadays [9-11]. Soluble lipases can also be used under mild reaction conditions, have a faster reaction time, display higher conversion rates than immobilized enzymes [9], and allow, without any fatty acid methyl esters (FAMEs) yield loss, the presence of water in the process, which is required for oil pretreatment or during downstream steps [11]. Furthermore, liquid lipases can be produced and sold at a much lower price [12,13], and can also be re-used after recovery from the glycerin phase. For instance, Callera Trans L maintained up to $95 \%$ activity after recycling (AR Madsen, personal communication). But in contrast with immobilized lipases, the necessary number of re-uses of liquid lipases could be much lower due to the large difference in price of both types of enzymes. The use of liquid instead of immobilized enzyme has resulted in a significant simplification of oil transesterification and is the background for the new, cost-effective process developed by Novozymes (Bagsværd, Denmark) using liquid lipase Callera Trans L, which is now being scaled-up at several production plants for biodiesel synthesis from different feedstocks [14].

Nowadays, biodiesel is mainly produced by transesterification of edible oils such as those from soybean, rapeseed, sunflower, or palm [15]. The cost of feedstocks is another important economical factor in biodiesel production, which indicates that selection of the appropriate raw material is of major importance for ensuring the feasibility of the process at industrial scale [16]. Thus, exploring the use of low value or non-edible feedstocks is a goal for biodiesel producing partners. In this context, non-refined (crude) soybean oil is an alternative solution already investigated for enzymatic transesterification $[6,11,17]$. However, crude, non-degummed oils contain impurities as phosphorous compounds (phospholipids), which have to be removed for efficient transesterification. Crude soybean oil generally has a phosphorus (gums) content of 800 to 1,200 ppm, equivalent to 2 to $3 \%$ of phospholipids [18], which can cause problems during storage due to precipitate formation and water accumulation. Moreover, according to the legal specifications, phosphorus concentration in final biodiesel must be reduced to less than $10 \mathrm{ppm}$ (EN14214:2003; ASTM D6751:2012). For biodiesel production, a high content of phospholipids in the raw feedstocks means a concomitant loss of yield in FAMEs production, as the fatty acids enclosed into the phospholipid molecules are not accessible to the lipase for transesterification. Phospholipids are commonly removed by previously developed refining/degumming processes of physical or chemical nature. In the 1990s the first industrial enzymatic oil-degumming process was launched with EnzyMax (Lurgi AG, Frankfurt, Germany), based on phospholipase conversion of non-hydratable phospholipids (NHPs) to hydratable lyso-phospholipids [19]. NHPs, which consist of phospholipids combined with metal cations, such as $\mathrm{Ca}^{2+}$ or $\mathrm{Mg}^{2+}$, can be chemoenzymatically converted into hydratable compounds and simply removed by water washing and centrifugation [20]. The easily hydratable phospholipids are phosphocholine (PC), phosphatidylinositol (PI), and lysophosphatidylcholine (LPC), whereas phosphatidylethanolamine (PE) and phosphatidic acid (PA) are generally considered as NHPs [21]. A guideline for industrial enzymatic degumming was reported by Cowan and Nielsen in 2008, suggesting a first step of citric acid treatment, where the acid is distributed with a high-shear mixer in the oil at high temperatures, to chelate the metals and to open the phospholipid micelles; following the citric acid treatment, the oil is cooled down to the optimal temperature for a final phospholipase treatment. Water (up to 1.5 to $2.5 \%$ ) is added together with the enzyme and sodium hydroxide, and the enzymatic reaction is carried out for 2 to $6 \mathrm{~h}$ [18].

Different types of microbial phospholipases have been described depending on the acyl ester bond they hydrolyze in the phospholipid molecule [22], which could be applied to enzymatic degumming. Phospholipase $A_{1}\left(P L A_{1}\right)$, which catalyzes the hydrolysis of the fatty acid at position 1 in the phospholipid molecule, releasing a lyso-phospholipid and a free fatty acid (FFA), has already been applied to the degumming process $[18,22,23]$ also in combination with phospholipase C (PLC), which cleaves the phosphorus-oxygen bond between glycerol and phosphate, releasing a diacylglycerol (DAG) and the phosphate ester group [24].

To search for a more sustainable, economic, and competitive process for biodiesel production, in this work we tested two phospholipases (PLA $\mathrm{P}_{1}$ and PLC), a lyso-phospholipase (LLPL-2), and their combinations, with the previously reported liquid lipase Callera Trans $\mathrm{L}$ in order to unify the enzymatic oil degumming with the transesterification, aimed at producing a final biodiesel that meets the phosphorus legal limits. Degumming and transesterification processes were studied combined or separately to define the optimal conditions for each enzyme applied (summarized in Table 1), and two main parameters were studied: the effect of methanol, necessary for the transesterification, on phospholipases, and the effect of citric acid, usually used as helper in oil degumming, on lipase activity. Crude soybean oil was used to set up the general conditions of the process, which was additionally tested on other difficult raw materials to analyze possible drawbacks. 
Table 1 Properties and working conditions in transesterification and degumming of all enzymes used

\begin{tabular}{|c|c|c|c|c|}
\hline \multirow{3}{*}{$\begin{array}{l}\text { Enzyme } \\
\text { Commercial name }\end{array}$} & \multirow{3}{*}{$\begin{array}{l}\text { Transesterification } \\
\text { Lipase } \\
\text { Callera Trans }{ }^{\circledR} \text { L (Novozymes A/S) }\end{array}$} & \multicolumn{3}{|c|}{ Enzymatic degumming } \\
\hline & & Phospholipase $A_{1}$ & Phospholipase C & Lyso-phospholipase \\
\hline & & Lecitase $^{\circledast}$ Ultra (Novozymes A/S) & Purifine $^{\circledast}$ (Verenium) & LLPL-2 (Novozymes A/S) \\
\hline $\mathrm{pH}$ & 5 & 4.5 to 5.5 & 7 & 4.5 to 4.8 \\
\hline Temperature & $35^{\circ} \mathrm{C}$ & 50 to $55^{\circ} \mathrm{C}$ & $60^{\circ} \mathrm{C}$ & 40 to $45^{\circ} \mathrm{C}$ \\
\hline Time reaction & $24 \mathrm{~h}$ & 4 to $6 \mathrm{~h}$ & $2 \mathrm{~h}$ & \\
\hline Dosage & $1 \%$ & 30 ppm & 200 ppm & 250 to $500 \mathrm{ppm}$ \\
\hline $\mathrm{H}_{2} \mathrm{O}$ required & 2 to $3.5 \%$ & $3 \%$ & 1 to $4 \%$ & \\
\hline Methanol $^{a}$ & 1.5 eqs & & & \\
\hline Acid pretreatment ${ }^{b}$ & & \multicolumn{3}{|c|}{ 0.065\% Citric acid/0.025\% Phosphoric acid } \\
\hline Caustic neutralization $^{\mathrm{b}}$ & & & 2 eqs $\mathrm{NaOH}$ & \\
\hline
\end{tabular}

\section{Results and discussion}

Citric acid effect on lipase activity

Citric acid, due to its chelating action towards $\mathrm{Ca}^{2+}$ and $\mathrm{Mg}^{2+}$ ions, is used as helper in degumming for disruption of phospholipid micelles $[18,23]$. Aimed at combining degumming and transesterification in the same pot, the influence of citric acid in the reaction system was a determining parameter studied here. A main point of interest was to investigate how citric acid might affect transesterification and lipase activity, in relation to $\mathrm{pH}$ variations. Accordingly, the $\mathrm{pH}$ effect on FAMEs production was analyzed by response surface methodology (RSM), by adding different amounts of $\mathrm{NaOH}$ to the reaction mixture, according to the patterns described in Table 2, which also includes the experimental response obtained for FAMEs production. Figure 1 shows the prediction profile for FAMEs content after citric acid use in soybean oil, obtained from the data analysis performed with JMP software (SAS Institute Inc., Cary, NC, USA). A clear negative effect of citric acid on transesterification, determined as a significant value (prob $>|t|=<0.0001$ ), was observed (Figure 1, left plot). Maximum production with citric acid was achieved when 2 eqs of $\mathrm{NaOH}$ were added for neutralization, but only 67\% FAMEs release was obtained under such conditions. The central plot in Figure 1 shows the effect of $\mathrm{pH}$ controlled by caustic neutralization: using 2 eqs of $\mathrm{NaOH}$ (corresponding to $270 \mathrm{ppm}$ ) to balance the effect of citric acid, resulting in a $\mathrm{pH}$ of 5 (D Cowan, personal communication), and optimal conditions for lipase Callera Trans L, a good biodiesel release should be achieved. However, despite the slight increase of the percentage of FAMEs with the increase of added $\mathrm{NaOH}$, still a too low biodiesel production was reached. The right plot in Figure 1 shows that 10 or 20 extra ppm of $\mathrm{NaOH}$, generally used with some difficult raw materials for a more efficient biodiesel production, had no effect on transesterification. Even though FAMEs production with phosphoric acid was higher than with citric acid
(Figure 1, left plot), transesterification was not complete, as it has been described that Callera Trans L, used under optimum reaction conditions, can reach $>95 \%$ transformation [11]. Moreover, use of phosphoric acid in an industrial biodiesel production plant could be a problem due to its toxicity; for this reason citric acid is nowadays being used in industrial degumming processes. As shown above (Figure 1), the effect of $\mathrm{pH}$ on the enzyme was not strongly significant, suggesting that the lipase inhibition effect observed when phosphoric acid was

Table 2 Experimental plan and results (FAMEs release) from testing acid, $\mathrm{NaOH}$ addition, and $\mathrm{NaOH}$ excess additions

\begin{tabular}{lcccc}
\hline Pattern & \multicolumn{3}{c}{ Variables } & Response \\
\cline { 2 - 4 } & X1 (acid) & $\begin{array}{c}\text { NaOH } \\
\text { (eqv) }\end{array}$ & $\begin{array}{c}\text { Extra NaOH } \\
\text { (ppm) }\end{array}$ & FAMEs (\%) \\
\hline 212 & Phosphoric acid & 1 & 10 & 84.3 \\
132 & Citric acid & 2 & 10 & 67.8 \\
222 & Phosphoric acid & 1.5 & 10 & 83.9 \\
131 & Citric acid & 2 & 0 & 67.1 \\
232 & Phosphoric acid & 2 & 10 & 84.7 \\
211 & Phosphoric acid & 1 & 0 & 78.8 \\
231 & Phosphoric acid & 2 & 0 & 77.6 \\
112 & Citric acid & 1 & 10 & 67.0 \\
121 & Citric acid & 1.5 & 0 & 77.3 \\
221 & Phosphoric acid & 1.5 & 0 & 79.5 \\
122 & Citric acid & 1.5 & 10 & 53.6 \\
213 & Phosphoric acid & 1 & 20 & 91.1 \\
113 & Citric acid & 1 & 20 & 51.3 \\
111 & Citric acid & 1 & 0 & 43.5 \\
133 & Citric acid & 2 & 20 & 71.1 \\
123 & Citric acid & 1.5 & 20 & 82.2 \\
223 & Phosphoric acid & 1.5 & 20 & 85.6 \\
233 & Phosphoric acid & 2 & 20 & 79.5 \\
\hline & & &
\end{tabular}




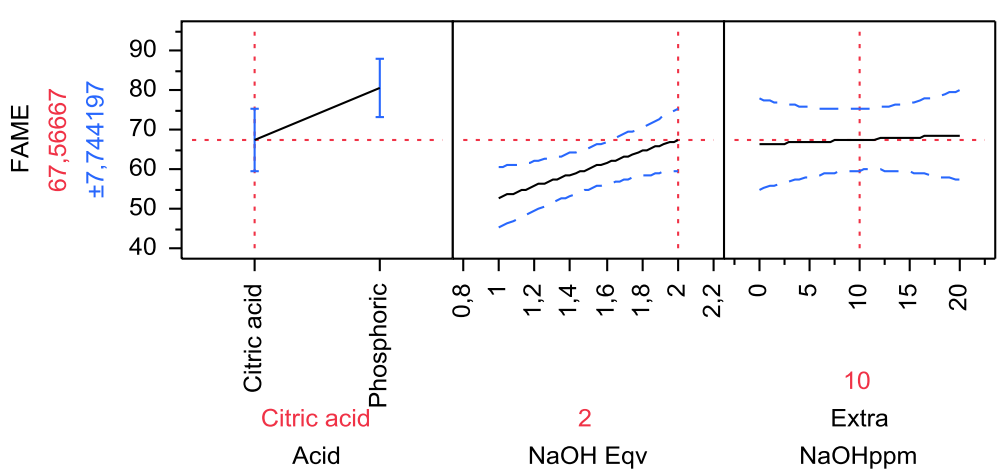

Figure 1 Prediction profile for citric acid obtained from RSM analysis. Graphical plotting of the effect of citric/phosphoric acid, pH, and extra NaOH on FAME production, made with JMP software (SAS Institute Inc.) (Rs = 0.88). FAME, fatty acid methyl ester; RSM, response surface methodology.

used could be due to a too strong chelating effect that might remove metal ions from the enzyme molecule, necessary for tertiary structure folding. Otherwise, a direct competition of the acid molecules with the substrate for the catalytic site of the enzyme could be hypothesized. Given the limited FAMEs production obtained when an acid was present in the system, in the following combined degumming/transesterification process, we decided to avoid the acid treatment, opting out for a good transesterification rate instead of an optimum content of phosphorus in the final biodiesel.

\section{Effect of methanol on degumming}

The second main parameter to be investigated for the combined degumming and transesterification reaction was the possible phospholipase inhibition due to the presence of methanol in the reaction mixture. In order to preserve the stability of the lipase, methanol was pumped into the reaction mixture following a slow continuous gradient of $0.4 \mathrm{ml} / \mathrm{h}$ during $10 \mathrm{~h}$, for a total amount of 1.5 molar equivalents of methanol to the total fatty acids (in glycerides and FFAs) in the oil. Taking into consideration that during an efficient transesterification reaction methanol is consumed by the lipase to form methyl esters, this compound is never present in the reaction mixture at the amount of 1.5 eqs. Knowing that 1 eq of methanol is required for a theoretical complete transesterification, the maximum amount of methanol left in the system that might inhibit phospholipases, would be 0.5 eqs.

To investigate the effect of methanol on phospholipases, a normal degumming process, including the conventional citric acid step, on soybean oil was carried out with addition of 0.5 eqs methanol during $10 \mathrm{~h}$. Reactions were incubated for $24 \mathrm{~h}$ at $35^{\circ} \mathrm{C}$, simulating a combination of the two processes. All phospholipases and the corresponding control samples were tested in the same trials with and without methanol, as specified in Table 3, and the final phosphorous content was determined. To avoid any artifacts due to the recovery method upon phospholipids precipitation, samples were analyzed both directly from the stopped reaction (data not shown) and after methanol evaporation (Table 3). Final phosphorus content was measured by inductively coupled plasma optical emission spectrometry (ICP-OES) and expressed in $\mathrm{ppm}$. For the two recovery conditions used, higher phosphorus values were found in the presence of methanol for all enzyme mixtures tested. Higher phosphorus amounts appeared as well after incubation of the original raw material with methanol, suggesting a direct action of methanol on the phospholipids from soybean oil and excluding any kind of phospholipase inhibition due to methanol.

In order to better see the effect of methanol on phospholipids and to investigate the combined action of citric acid and methanol, these assays were repeated using excess methanol (1.5 eqs), added to the simple raw material and to citric acid-treated oil. The corresponding reaction mixtures appeared as shown in Figure 2 after centrifugation. Comparison of batches 1 (no methanol) and 2 (with methanol) containing untreated raw material

Table 3 Phosphorus content of samples treated or untreated with methanol

\begin{tabular}{lcc}
\hline Condition & Without $\mathbf{M e O H}$ & With $\mathbf{M e O H}$ \\
\hline Raw oil $^{a}$ & 64 & 575 \\
$\mathrm{AD}^{\mathrm{b}}$ & $<5$ & 18 \\
$\mathrm{AD}+\mathrm{PLA}_{1}^{c}$ & $<5$ & 5 \\
$\mathrm{AD}+\mathrm{PLC}^{\mathrm{C}}$ & $<5$ & 7 \\
$\mathrm{AD}+\mathrm{PLA}_{1}+\mathrm{PLC}$ & $<5$ & $<5$ \\
$\mathrm{AD}+\mathrm{PLA}_{1}+\mathrm{LLPL}^{\mathrm{C}}$ & $<5$ & 14
\end{tabular}

${ }^{\mathrm{a}}$ Soybean oil with approximately $900 \mathrm{ppm} \mathrm{P;}{ }^{\mathrm{b}} \mathrm{AD}$ batch where only the acid degumming step followed by caustic neutralization was performed; ' ${ }^{c}$ complete degumming: acid treatment, caustic neutralization, and enzymatic reactions with different phospholipases. Phosphorus content expressed in ppm. AD, acid degumming; PLA 1 , phospholipase $\mathrm{A}_{1} ; \mathrm{PLC}$, phospholipase $\mathrm{C}_{\text {; }}$ LLPL-2, lyso-phospholipase. 
clearly reflects the effect of methanol on gums removal. When methanol was present (batch 2) the oil phase was completely clear and no sediment could be observed. Oil clarification was also observed when citric acid degumming was applied (batch 3 ), but in this case a sediment formation appeared, suggesting gums precipitations. Batch 4, containing both citric acid and methanol in the reaction mixture, displayed a non-transparent oil phase resulting probably from a contrasting effect on phospholipids solubility due to the double treatment. From the results obtained, and in agreement with previous reports derived from other studies, we can conclude that methanol seems to solubilize the phospholipids of soybean oil [25]. Furthermore, soybean oil phospholipids are mainly constituted by PC (and to a lower extent by $\mathrm{PE})$, described as easily hydratable phospholipids and also soluble in short chain alcohols like ethanol [26]. Thus, their solubility in methanol would also be possible and is in agreement with the results obtained here.

Given the widespread use of soybean oil in industrial biodiesel production, the evidence of solubilization of phospholipids by methanol acquires a great importance in the process. It means that gums can be dissolved by methanol, with no requirement for a conventional acid treatment, thus making the released phospholipids more available for enzymatic transesterification, that is, methanol seems to break apart the micelles. Therefore, presence of methanol, used here as a substrate, may allow to abolish the acid degumming step without any loss of performance. This assumption was demonstrated with the combination of enzymatic degumming and

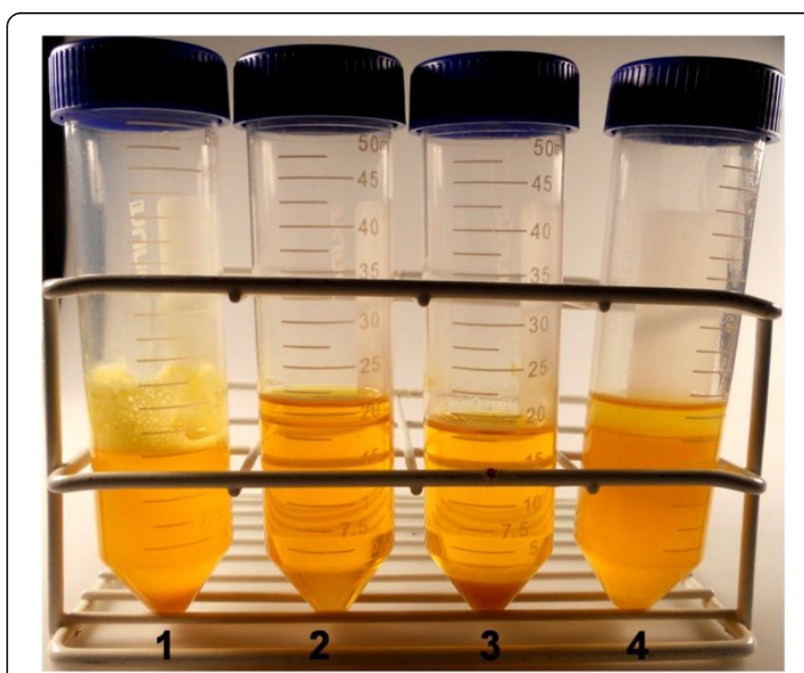

Figure 2 Dissolving effect of methanol on oil gums. (1) Soybean oil (raw material); (2) soybean oil with 1.5 eqs $\mathrm{MeOH}$; (3) soybean oil acid degummed; and (4) soybean oil acid degummed with 1.5 eqs $\mathrm{MeOH}$. Image obtained after $24 \mathrm{~h}$ incubation at $35^{\circ} \mathrm{C}, 250 \mathrm{rpm}$ agitation, and centrifugation at 2,000 rpm for $5 \mathrm{~min}$. transesterification, performed without citric acid treatment, as described in the following sections.

\section{Combining enzymatic degumming and transesterification} Oil degumming is a requirement to obtain refined, edible oils, but it is also essential for biodiesel production. For immobilized Candida antarctica lipase, Watanabe and co-workers reported that crude (non-degummed) oil does not undergo enzymatic-catalyzed methanolysis [6]. Depending on the raw materials used, degumming becomes an indispensable step for biodiesel production to achieve phospholipids removal and to reduce the final phosphorus content below the specified limits. In addition to an extra tank, the degumming process involves the use of acids and high temperatures, all factors boosting the process costs. Moreover, during the degumming process there is an unavoidable loss of oil that migrates to the gums during removal. For instance, for crude soybean oil containing an average 900 ppm P, gums represent a 2.5\% loss of total oil; being the current market price US $\$ 1,100$ per ton, this corresponds to a loss of US\$27.5 per ton of oil. These drawbacks could be overcome with the unification of degumming and transesterification in the same tank [18]. For this purpose, a single-step enzymatic degumming and transesterification process using phospholipases and liquid lipase Callera Trans L, with no need for a conventional acid degumming treatment, could provide a solution to such problems.

Since citric acid has a negative effect on FAMEs production (Figure 1), and taking into consideration the role of methanol in phospholipid solubilization shown above (Figure 2), enzymatic degumming with phospholipases was coupled to transesterification in the same batch, using Callera Trans L best operating conditions $(24 \mathrm{~h}$ incubation, $\left.35^{\circ} \mathrm{C}, 250 \mathrm{rpm}\right)$. Even though in some cases, as for PLC, optimal $\mathrm{pH}$ and temperature conditions were different from those of Callera Trans L (Table 1), the prolonged reaction time could compensate for the slower catalysis rate of such phospholipase. Performance of different types of phospholipases was tested and the final results for FAMEs production and phosphorus content are listed in Table 4. From the point of view of final phosphorus content, it is remarkable the high $\mathrm{P}$ concentration found in the oil phase when only transesterification (TE), used as a control, was run. For this sample, after the reaction and recovery by mild centrifugation, the phosphorus content was approximately the same as that of raw material $(823 \mathrm{ppm})$, suggesting that Callera Trans L does not have hydrolytic phospholipase activity. Moreover, FAMEs formation in that case was not complete, with only $85 \%$ FAMEs production achieved. The transesterification yield increased drastically, to reach $>95 \%$ FAMEs, when phospholipases were applied to the reaction mixture, especially when $\mathrm{PLA}_{1}$ was present (Table 4). At the same 
Table 4 Biodiesel resulting from the combined degumming/transesterification process

\begin{tabular}{|c|c|c|}
\hline Condition & FAMEs $^{\mathrm{a}}$ & $\mathrm{P}^{\mathrm{b}}$ \\
\hline$\overline{\mathrm{TE}}$ & $85.2 \pm 1.4$ & $823 \pm 56$ \\
\hline $\mathrm{PLA}_{1}+\mathrm{TE}$ & $98.2 \pm 2.1$ & $8.0 \pm 3.0$ \\
\hline $\mathrm{PLC}+\mathrm{TE}$ & $90.8 \pm 4.0$ & $12.8 \pm 1.8$ \\
\hline$P L A_{1}+L L P L-2+T E$ & $97.8 \pm 0.3$ & $6.0 \pm 3.0$ \\
\hline$P L A_{1}+P L C+T E$ & $96.6 \pm 0.8$ & $4.6 \pm 1.7$ \\
\hline
\end{tabular}

${ }^{a}$ FAMEs production measured as percentage; ${ }^{b}$ phosphorus content expressed in ppm. All data are the mean of three different trials. FAME, fatty acid methyl ester; LLPL-2, lyso-phospholipase; PLA, phospholipase $A_{1} ;$ PLC, phospholipase C; TE, transesterification.

time, a dramatic phosphorus content decrease, below $10 \mathrm{ppm}$, was found in all reaction mixtures including phospholipases. The only exceptions were those reactions containing solely PLC and Callera Trans L. For those samples FAMEs production resulted in approximately $90 \%$, and remaining phosphorus was $12 \mathrm{ppm}$. The highest FAMEs production in samples containing combinations of phospholipases could be explained by a synergic effect between phospholipases and the lipase during the process. PLA would first release a FFA from a phospholipid molecule, making it available for lipase esterification with methanol, a fact that has already been reported for Callera Trans L, which shows an excellent esterification activity [11]. Therefore, through a synergic mechanism, phospholipase activity leads to a gain of oil useful for lipase-mediated esterification. Thus, beyond the reduction of phosphorus in the final biodiesel, phospholipases contribute to the release of FFAs from phospholipid molecules, which can then be used by the lipase for FAMEs formation. Moreover, when a lysophospholipase (LLPL-2) was added to help PLA 1 in reducing the final content of phospholipids, the phosphorus values found were even lower. This can be explained by the mode of action of LLPL-2, which releases the FFA located at position 2 left by $\mathrm{PLA}_{1}$ activity on the phospholipid molecule. After the combined action of PLA 1 and LLPL-2, a glycerol-phosphatide is liberated (Figure 3) which, being more polar than a lyso-phospholipid, migrates to the glycerol phase, thus reducing the phosphorus content in the oil phase. Higher reductions of phosphorus could be observed when PLA 1 was combined with PLC. PLC directly cuts the phosphodiester group, releasing a DAG (Figure 3), also known to be a good substrate for Callera Trans L [11]. FAMEs production and phosphorus reduction when only PLC was applied resulted in values lower than in other reactions, a fact that can be justified by the selectivity of this enzyme for only two kinds of phospholipids (PC and PE) [27]. Furthermore, PLC was the enzyme working in the worst conditions in the combined process, as it was used far from its optimum temperature. Despite that, we can point to PLC as an ideal helper of $\mathrm{PLA}_{1}$ in the combined process developed. Figure 3 graphically represents the enzyme activities mentioned and summarizes the polarity of the species released. Among them, glycerol and polar molecules containing the remaining phosphorus, like the glycerol-phosphatide and the phosphodiester group

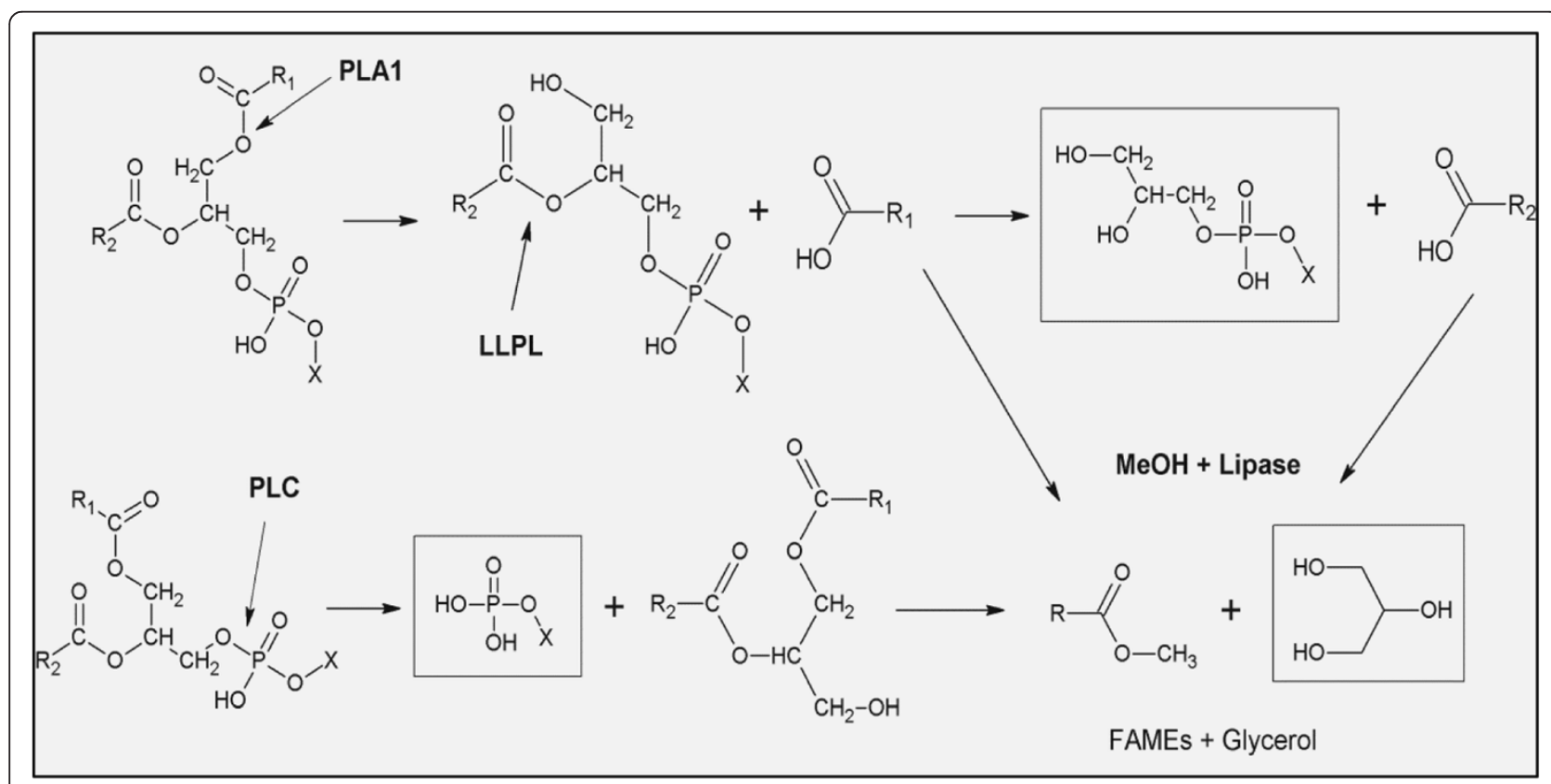

Figure 3 Enzymatic activities in the combined process. Schematic representation of all possible enzymatic activities involved in the combined degumming/transesterification process. Polar glycerol-phosphatide, resulting from PLA 1 LLPL-2 activities, and the phosphodiester group resulting from PLC cleavage, migrate to the aqueous phase together with the glycerine produced during transesterification (polar compounds highlighted by rectangles). LLPL-2, lyso-phospholipase; PLA, phospholipase $A_{1}$; PLC, phospholipase C. 
(enclosed in rectangles), are shown, which are easily separated into the glycerin phase. This explains the good reduction of phosphorus content achieved in the final biodiesel for samples treated with the enzyme combinations assayed. The proposed activity of the phospholipases tested and their released products was further confirmed after study of the phosphatides composition of the oil and glycerin phases resulting from the combined reactions performed.

\section{Study of phospholipases activity}

Analysis of phosphatides by ultra-performance liquid chromatography tandem mass spectrometry (UPLC/MS/ MS) in the oil and glycerin phases obtained from the combined reactions, confirmed the enzymatic activity of phospholipases, excluding the possibility that the phospholipids present in the original raw material were separated to the glycerin phase or to the interphase as entire molecules, without any gain of oil for further lipasecatalyzed transesterifications.

Comparing the oil phase of control samples containing only Callera Trans L (TE), where only transesterification occurs, with that resulting from reactions containing both the lipase and $\mathrm{PLA}_{1}\left(\mathrm{PLA}_{1}+\mathrm{TE}\right)$, it can be observed that peaks corresponding to intact phospholipids containing $\mathrm{PC}$ ( $\mathrm{RT}=15$ to $24 \mathrm{~min}$ region) completely disappeared (Figure 4), indicating that $\mathrm{PLA}_{1}$ activity almost completely removed all PC from the oil phase. Interestingly, peaks corresponding to LPC $(\mathrm{RT}=3$ to 5 min region), apparently present in the oil from the beginning, disappeared after $\mathrm{PLA}_{1}+\mathrm{TE}$ treatment, suggesting a kind of extra activity of $\mathrm{PLA}_{1}$, which in this case seems to be able to process also the fatty acid of the LPC molecule and not only the one at position sn-1 as would be expected. This extra activity, not described before for a PLA 1 , could be due to the long reaction time used for the combined process: generally phospholipases are used for 2 to $6 \mathrm{~h}$ (Table 1), while in our system, they were acting during $24 \mathrm{~h}$.

The final glycerin composition of all samples was analyzed for each type of phosphorous compound, and the mode of action of the phospholipases used could be confirmed (see Additional files 1, 2, 3, 4, and 5). As expected, PC (RT = $5 \mathrm{~min} ; \mathrm{m} / \mathrm{z} 184$ ) could be found only in the glycerin phase derived from the reactions where PLC was present $\left(\mathrm{PLC}+\mathrm{TE}\right.$ and $\left.\mathrm{PLA}_{1}+\mathrm{PLC}+\mathrm{TE}\right)$, proving the specific activity of this phospholipase for the phosphodiester bond (see Additional file 3 and Additional file 5). Instead, as a result of $\mathrm{PLA}_{1}$ activity, lyso-phosphocholine should appear at $\mathrm{RT}=1.88 \mathrm{~min}$, extracting ions 496.3, $518.3,520.3$, and $522.3 \mathrm{~m} / \mathrm{z}$ (corresponding to LPC bearing the $16: 0,18: 1,18: 2$, or $18: 3$ fatty acids, respectively), but it could also be detected in very small amounts in all glycerin samples, suggesting a kind of instability of the LPC molecule. In fact, looking at glycerol-phosphocholine ( $\mathrm{RT}=11 \mathrm{~min} ; \mathrm{m} / \mathrm{z} 258)$, this product should be present only in the glycerin phase of the reaction $\mathrm{PLA}_{1}+$ LLPL- $2+$ TE, resulting from the combined activity of these enzymes. Nevertheless, it was also found in all other samples, supporting the hypothesis of an extra activity of $\mathrm{PLA}_{1}$ in processing the fatty acid at position sn-2, or being the consequence of a kind of instability of the LPC molecule (see Additional files 1, 2, 3, 4, and $5)$. However, LLPL-2 activity could be confirmed by the peak of glycerol-phosphocholine found in sample $\mathrm{PLA}_{1}+\mathrm{LLPL}-2+\mathrm{TE}$, which was in fact higher than that found for the other samples (see Additional file 4). From these results we can conclude that parallel analysis by UPLC/MS/MS of the phosphatides found in the oil and glycerin phases, resulting from the combined reactions performed, turned out as a powerful tool for the study of such a complex system, and allowed to isolate the activity of each enzyme applied, confirming the importance of phospholipases in the combined degumming and transesterification process.

\section{Combined degumming/transesterification process using crude, difficult vegetable oils}

The corn oil used here derived from a biorefinerybioethanol plant production, and is obtained directly from dry corn milling during the ethanol process. The oil is isolated after fermentation and centrifugation, and is not degummed in the traditional sense, although it is somehow physically and chemically degummed throughout the ethanol process. This oil has a phosphorous content of 62 ppm, mostly constituted by hydratable phospholipids. Used as a substrate for combined enzymatic degumming and transesterification, it resulted in a slightly lower FAMEs production, compared to soybean oil. Optimum operational conditions for such corn oil were obtained with the combination PLA $_{1}+$ LLPL-2 + TE, showing 96.2\% release of FAMEs. Transesterification with corn oil could not be complete due to the composition of this substrate, rich in sterols, acylglycerides, and waxes, which probably are not processed by the lipase for methyl esterification. Nevertheless, the rate of FAMEs production with this oil is still $>95 \%$, as required by the biodiesel specifications. Like for soybean oil, phospholipases helped to increase the transesterification yield, as shown in Table 5. For all conditions tested, the final phosphorus values obtained after reactions were below $10 \mathrm{ppm}$, even when phospholipases were not present in the reaction mixture. This is mostly due to the low initial content of phosphorus in the corn oil and indicates that such phospholipids are mostly hydratable and easily removed by simple washing with the water present in the system. However, when a phospholipase is present in the reaction mixture, phospholipids are hydrolyzed and 

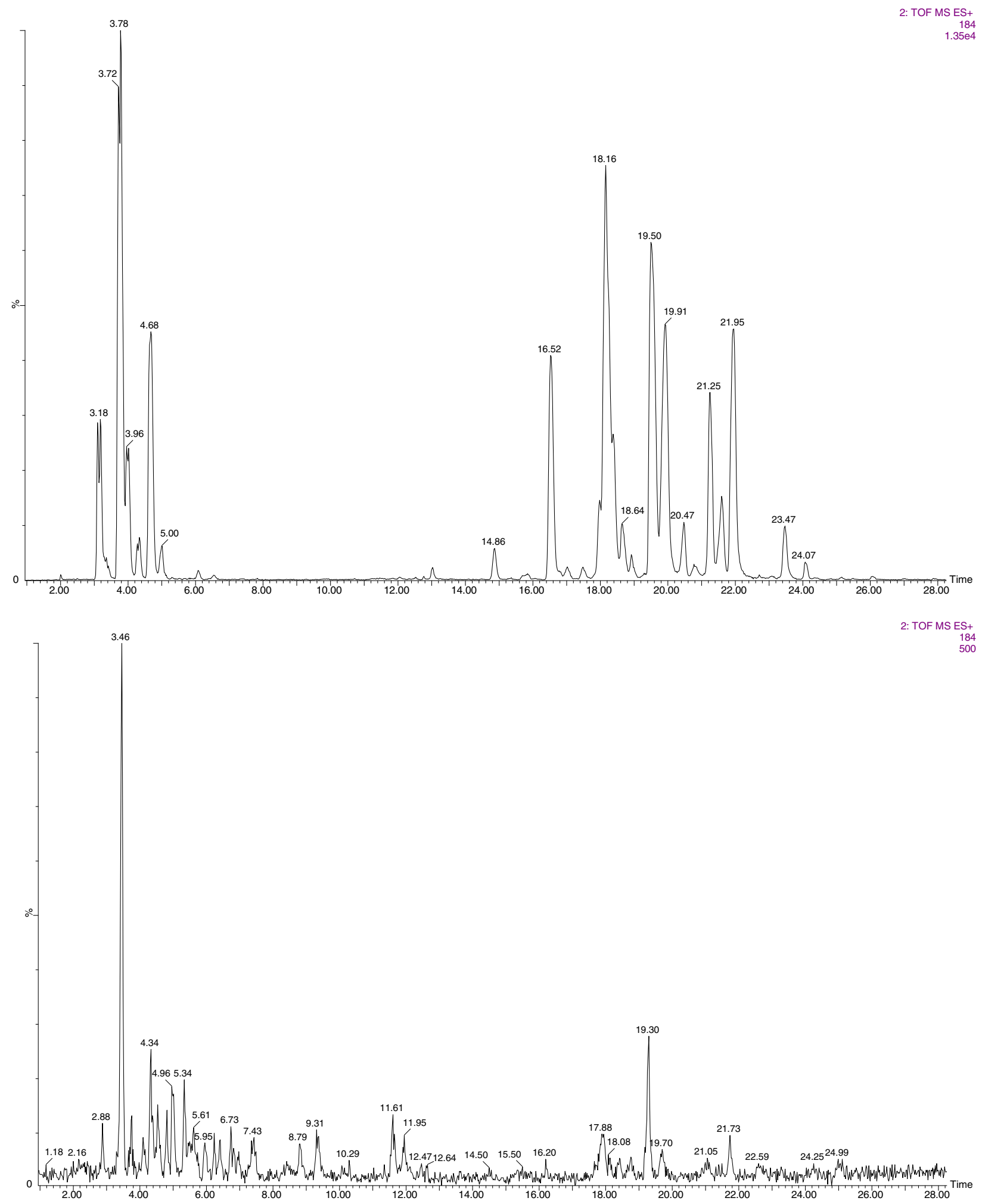

Figure 4 UPLC/MS/MS analysis of the oil phase. Comparison of the mass spectrum resulting from analysis of the oil phase of reactions TE (upper plot) and PLA + TE (bottom plot). Samples were run with a RP column. For both chromatograms, ion $184 \mathrm{~m} / \mathrm{z}$ in positive MS/MS mode were extracted. MS/MS, tandem mass spectrometry; PLA 1 , phospholipase $A_{1}$; RP, reverse phase; TE, transesterification; UPLC, ultra-performance liquid chromatography. 
Table 5 Combined degumming/transesterification biodiesel process applied to difficult oils

\begin{tabular}{lccccc}
\hline & \multicolumn{2}{c}{ Corn Oil } & & \multicolumn{2}{c}{ Canola oil } \\
\cline { 2 - 3 } \cline { 5 - 6 } Condition & FAMEs $^{\mathbf{a}}$ & $\mathbf{P}^{\mathbf{b}}$ & & FAMEs $^{\mathbf{a}}$ & $\mathbf{P}^{\mathbf{b}}$ \\
\hline TE & 93.4 & 7.5 & 98.7 & 145 \\
PLA $1+T E$ & 94.5 & 7.3 & 98.3 & 142 \\
PLC + TE & 95.7 & 9.2 & 98.2 & 130 \\
PLA $1+$ LLPL-2 + TE & 96.2 & 9.3 & 98.9 & 145 \\
PLA $_{1}+$ PLC + TE & 95.5 & 7.5 & 99.1 & 130 \\
\hline
\end{tabular}

${ }^{\mathrm{a}}$ FAMEs production measured as percentage; ${ }^{\mathrm{b}}$ final phosphorus content expressed in ppm. FAME, fatty acid methyl ester; LLPL-2, lyso-phospholipase; $\mathrm{PLA}_{1}$, phospholipase $\mathrm{A}_{1} ; \mathrm{PLC}$, phospholipase $\mathrm{C} ; \mathrm{TE}$, transesterification.

more useful oil is available for lipase methyl ester formation.

When crude canola oil was used, a high transesterification rate was achieved but the final phosphorus content was not reduced below $130 \mathrm{ppm}$ (Table 5). This oil is known to have a very high content of $\mathrm{Ca}^{2+}$ and $\mathrm{Mg}^{2+}$, and is especially difficult to degum. Crude canola oil is considered one of the most difficult oils for degumming because it is mostly composed by NHPs. These NHPs are barely attacked by phospholipases without the aid of an acid treatment. Moreover, they need a strong chelating agent such as citric acid at higher concentrations $(0.1 \%)$ to achieve a suitable phosphorus reduction. These conditions can hardly be reached with milder conditions of citric acid or even with phosphoric acid (D Cowan, personal communication), thus making it difficult to reach the required phosphorus content in the final biodiesel.

\section{Conclusions}

A successful, completely enzymatic process has been investigated resulting in a more economic and eco-friendly biodiesel production. Combination of crude oil degumming and transesterification in a unique step is possible by using phospholipases and liquid lipase Callera Trans L. In the combined process, an important cost reduction can be achieved. In addition to the US\$27.5 per ton savings in the case of soybean oil, costs can be substantially lowered by avoiding the extra tank commonly required for oil degumming pretreatments, and by using mild temperatures $\left(35^{\circ} \mathrm{C}\right)$. Moreover, citric acid treatment has been eliminated and only low sodium hydroxide concentrations are used, thus increasing the savings of the whole process. Therefore, the developed method meets the conditions for being easily scaled-up and is suitable for most crude vegetable oils.

\section{Methods}

\section{Substrates}

Crude soybean oil (FFA $=1 \% ; \mathrm{P}=900 \mathrm{ppm} ; \mathrm{pH}=6.8)$ was obtained from Cargill (Iowa Falls, IA, USA). Corn oil from bioethanol production (FFA $=6 \%$; $\mathrm{P}=62 \mathrm{ppm}$;
$\mathrm{pH}=4.5)$ was provided by Blue Sun (St Joseph, MO, USA). Crude canola oil (FFA $=1 \% ; \mathrm{P}=250 \mathrm{ppm}$; $\mathrm{pH}=$ 5.7) was kindly donated by Richardson (Winnipeg, MB, Canada). Crude soybean oil was chosen as a cheaper raw material and because it is still the most commonly used oil in the industrial biodiesel production. Corn oil was considered interesting for this study because it derives, as a residue, from the bioethanol industrial production, thus to close the hypothesis to unify both bioethanol/ biodiesel production processes. Finally, crude canola oil was tested to verify the potentialities of the suggested process towards oils rich in NHPs; the canola oil used here contained approximately $130 \mathrm{ppm}$ of $\mathrm{P}$ in NHPs over the total $250 \mathrm{ppm}$ of initial P content.

\section{Enzymes and chemicals}

Soluble lipase Callera Trans L, phospholipase $\mathrm{A}_{1}, \mathrm{PLA}_{1}$ (Lecitase ${ }^{\bullet}$ Ultra), and lyso-phospholipase, LLPL-2 (patent WO 2001027251 A1) used in this work were from Novozymes A/S. Phospholipase C, PLC (Purifine ${ }^{\circ}$ ) was purchased from Verenium (San Diego, CA, USA). All chemicals used were from Sigma Aldrich (St Louis, MO, USA).

\section{Enzymatic degumming}

When only enzymatic degumming was performed, an adaptation of the Cowan and Nielsen protocol was used]. Acid treatment was performed by adding citric acid $(0.065 \%)$ to $20 \mathrm{~g}$ of pre-heated oil $\left(55^{\circ} \mathrm{C}\right)$ and mixed with an Ultra Turrax T25 (IKA, Staufen, Germany) for $10 \mathrm{~s}$ at $12,000 \mathrm{rpm}$. The emulsion was incubated for $30 \mathrm{~min}$ at $55^{\circ} \mathrm{C}$ and $250 \mathrm{rpm}$ in a horizontal shaker. Caustic neutralization was performed with addition of $\mathrm{NaOH}$ ( 2 eqs to citric acid) and $3.5 \%$ water. Enzymatic degumming was completed by applying phospholipases, with the recommended dosage indicated in Table 1. Lyso-phospholipase was used only in combination with $\mathrm{PLA}_{1}$ at a concentration of $400 \mathrm{ppm}$. Combined degumming/transesterification reactions were run at $35^{\circ} \mathrm{C}$ for $24 \mathrm{~h}$ with $250 \mathrm{rpm}$ agitation, according to the optimum transesterification conditions, instead of the recommended incubation for degumming of $55^{\circ} \mathrm{C}$ for $2 \mathrm{~h}$.

\section{Transesterification reactions}

FAMEs synthesis reactions were carried out in $100 \mathrm{ml}$ squared bottles for $24 \mathrm{~h}$ at $35^{\circ} \mathrm{C}$ with $250 \mathrm{rpm}$ agitation in a horizontal shaker. The reaction mixtures consisted of $20 \mathrm{~g}$ oil, $1 \% \mathrm{w} / \mathrm{w}$ Callera Trans L lipase solution, 3.5\% $\mathrm{H}_{2} \mathrm{O}$, and $10 \mathrm{ppm}$ of $\mathrm{NaOH}$. Total methanol $(\mathrm{MeOH})$ per reaction was 1.5 eqs of oil, added continuously by a syringe pump system (SP220 IZ, WPI) with a flow rate of $0.4 \mathrm{ml} / \mathrm{h}$ during $10 \mathrm{~h}$. 
Table 6 UPLC/MS/MS analysis of phosphatide compounds used as standards

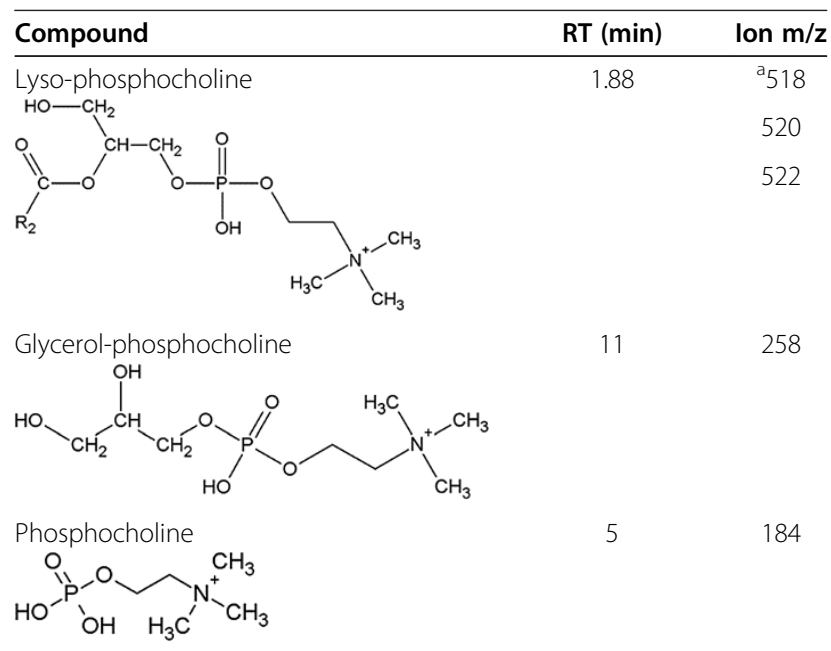

Ions corresponding to molecules containing a 18:1, 18:2, and 18:3 fatty acid chain, respectively. RT, retention time; UPLC/MS/MS, ultra-performance liquid chromatography tandem mass spectrometry.

\section{One-step enzymatic degumming and transesterification}

All enzymes (lipase and phospholipases) were added at a time to $20 \mathrm{~g}$ of oil. Reaction mixtures included water (3.5\%), $\mathrm{NaOH}(10 \mathrm{ppm})$, and 1.5 eqs of $\mathrm{MeOH}$, pumped in a linear gradient for $10 \mathrm{~h}$. Combination of degumming and transesterification was incubated following the transesterification conditions.

\section{Statistical design of experiments}

The effect of citric acid was studied by a RSM, where two variables were analyzed at three different levels: 1 ) choice of acid (citric/phosphoric); 2) the equivalents of $\mathrm{NaOH}$, necessary to balance the $\mathrm{pH}$ ( 1 to 1.5 to 2 eqs); and 3) extra $\mathrm{NaOH}$, generally helpful for transesterification of difficult oils (0 to 10 to $20 \mathrm{ppm}$ ). These conditions were combined with the citric/phosphoric acid possibility. Distribution of the experimental patterns analyzed is shown in Table 2. Each pattern corresponds to a single batch reaction, where the acid treatment, followed by caustic neutralization, was combined directly with the transesterification without any phospholipase addition. Citric acid, at a fixed concentration of $0.065 \% \mathrm{w} / \mathrm{w}$ of oil, or phosphoric acid at $0.025 \% \mathrm{w} / \mathrm{w}$, were added to $20 \mathrm{~g}$ of oil, mixed by high shearing and incubated for $30 \mathrm{~min}$ at $55^{\circ} \mathrm{C}$, with $250 \mathrm{rpm}$ agitation. After incubation, the oil was cooled down and Callera Trans $\mathrm{L}(1 \% \mathrm{w} / \mathrm{w})$ was added together with $3.5 \%$ water and $\mathrm{NaOH}$, as indicated in Table 2. Incubation was prolonged for $24 \mathrm{~h}$ at $35^{\circ} \mathrm{C}$ with a linear gradient pumping of methanol $(0.4 \mathrm{ml} / \mathrm{h}$ for $10 \mathrm{~h})$. Each pattern was analyzed for FAMEs production and final phosphorus content. Data were analyzed with JMP software (SAS Institute Inc.).

\section{Recovery methods}

Analysis of FAMEs production was performed by gas chromatography (GC). After $24 \mathrm{~h}$ incubation, $1 \mathrm{ml}$ reaction mixture was taken and evaporated in a Heto Vacuum concentrator at $60^{\circ} \mathrm{C}$ for $1 \frac{1}{2} \mathrm{~h}$ to remove excess methanol.

For phosphorus analysis, the whole reaction volume was transferred to a $50 \mathrm{ml}$ tube and centrifuged at low speed $(2,000 \mathrm{rpm})$ for $5 \mathrm{~min}$ to simulate the sedimentation step used to separate the final products in an industrial production plant. After centrifugation, $4 \mathrm{ml}$ were taken from the upper oil phase and analyzed through ICP-OES. The bottom phase (glycerin) was analyzed by UPLC/MS/MS to study the phosphatides composition resulting from the reactions.

\section{FAMEs determination}

Determination of FAMEs (\%) was performed according to the EN14103 standard method on a Varian Chrompack CP-3900 GC with flame ionization detectors (FIDs), equipped with a Varian 'Select Biodiesel for FAMEs' (30 m, 0.32 id) column. Methyl heptadecanoate was used as internal standard, as indicated by EN14103. The solution was prepared at a concentration of $10 \mathrm{mg} / \mathrm{ml}$ in acetone. After methanol evaporation, $50 \mathrm{mg}$ of the oil phase were used for each analysis.

\section{Phosphorus content quantification}

Phosphorus content was determined by the ICP-OES method at the department of Analytical Development, Novozymes (Kalundborg, Denmark). Accordingly, $0.2 \mathrm{~g}$ of each sample were initially destructed in $4.5 \mathrm{ml}$ concentrated $\mathrm{HNO}_{3}(69 \%)$ and heated for 4 to $5 \mathrm{~h}$ at $105^{\circ} \mathrm{C}$ for further dissolution in a total volume of $10 \mathrm{ml}$ Milli-Q water. Treated samples were analyzed in a Varian Vista MPX system for ICP, using yttrium as internal standard. Resulting data were processed with ICPExpert version 4.1 software, and phosphorus concentration expressed in $\mathrm{ppm}=\mathrm{mg} / \mathrm{kg}$.

\section{Analysis of phosphatides}

Phosphatides content in the oil and glycerin phase was analyzed by UPLC/MS/MS in a Q-Tof Premier (Waters, Milford, MA, USA). Two chromatographic systems were set up: one with a hydrophilic interaction liquid chromatography (HILIC) column (Acquity BEH Amide, $1.7 \mu \mathrm{m}, 2.1 \mathrm{~mm} \times 150 \mathrm{~mm}$ ), and the second with a reverse phase (RP) column (Acquity CSH C18, $1.7 \mu \mathrm{m}, 2.1 \mathrm{~mm} \times 100 \mathrm{~mm}$ ). Samples were analyzed in positive and negative mode on the UPLC-UV-Tof and data processed using MassLynx version 4.1 software (Waters). The RP-chromatography was set up with a $0.25 \mathrm{ml} / \mathrm{min}$ flow of eluent A containing acetonitrile/ isopropyl alcohol/HCOOH (50:50:0.15) and eluent $\mathrm{B}$ 
containing isopropyl alcohol/HCOOH (100:0.15). The gradient was running isocratic for $1 \mathrm{~min}$ at $99 \% \mathrm{~A}$, followed by a 49 min gradient to $1 \% \mathrm{~A}$. The $1 \% \mathrm{~A}$ was running isocratic for $5 \mathrm{~min}$, followed by a $5 \mathrm{~min}$ gradient back to initial settings (that is, 99\% A). The HILIC was set up with a $0.35 \mathrm{ml} / \mathrm{min}$ flow and an A-eluent with acetonitrile/HCOOH (100:0.15\%) and B-eluent with acetonitrile/MQ water/ $\mathrm{HCOOH}$ (50:50:0.15). The method was running isocratic for $20 \mathrm{~min}$ with $95 \% \mathrm{~A}$. For both procedures, the MS was set to scan from 95 to $1,500 \mathrm{~m} / \mathrm{z}$ ions in both positive and negative mode.

Commercial phosphorous compounds of choline (LPC, glycerol-phosphocholine, and PC) were chosen as standards and run in the UPLC/MS/MS with the HILIC column. Corresponding retention times and mass ion compositions are listed in Table 6. Glycerin samples analyzed were the same as those shown in Table 4 for the combined degumming and transesterification reactions using soybean oil.

\section{Additional files}

Additional file 1: UPLC/MS/MS analysis of phosphorous compounds found in the released glycerin after a degumming/transesterification reaction. Positive MS spectrum corresponding to TE sample, where only Callera Trans $L$ was present. LPC, glycerol-phosphocholine, and PC were analyzed by extracting ions 520,258 , and $184 \mathrm{~m} / \mathrm{z}$, respectively.

Additional file 2: UPLC/MS/MS analysis of phosphorous compounds found in the released glycerin after a degumming/transesterification reaction. Positive MS spectrum corresponding to PLA 1 + TE sample, where $P L A_{1}$ and liquid lipase Callera Trans $L$ were present. LPC, glycerol-phosphocholine, and PC were analyzed by extracting ions 520, 258, and $184 \mathrm{~m} / \mathrm{z}$, respectively.

Additional file 3: UPLC/MS/MS analysis of phosphorous compounds found in the released glycerin after a degumming/transesterification reaction. Positive MS spectrum corresponding to PLC + TE sample, where PLC and liquid lipase Callera Trans L were present. LPC, glycerol-phosphocholine, and PC were analyzed by extracting ions 520,258, and $184 \mathrm{~m} / \mathrm{z}$, respectively.

Additional file 4: UPLC/MS/MS analysis of phosphorous compounds found in the released glycerin after a degumming/transesterification reaction. Positive MS spectrum corresponding to PLA 1 + LLPL-2 + TE sample, where PLA $A_{1}$, Iyso-phospholipase 2, and liquid lipase Callera Trans $L$ were present. LPC, glycerol-phosphocholine, and PC were analyzed by extracting ions 520, 258, and $184 \mathrm{~m} / \mathrm{z}$, respectively.

Additional file 5: UPLC/MS/MS analysis of phosphorous compounds found in the released glycerin after a degumming/transesterification reaction. Positive MS spectrum corresponding to PLA 1 PLC + TE sample, where $P L A_{1}, P L C$, and liquid lipase Callera Trans $L$ were present. LPC, glycerol-phosphocholine, and PC were analyzed by extracting ions 520,258 , and $184 \mathrm{~m} / \mathrm{z}$, respectively.

\section{Abbreviations}

AD: Acid degumming; DAG: Diacylglycerol; FAME: Fatty acid methyl ester; FFA: Free fatty acid; FID: Flame ionization detector; GC: Gas chromatography; HILIC: Hydrophilic interaction liquid chromatography; ICP-OES: Inductively coupled plasma optical emission spectrometry; LLPL: Lyso-phospholipase; LPC: Lysophosphatidylcholine; MeOH: Methanol; MS/MS: Tandem mass spectrometry; NHP: Non-hydratable phospholipid; PA: Phosphatidic acid; PC: Phosphocholine; PE: Phosphatidylethanolamine; PI: Phosphatidylinositol; PLA : Phospholipase $A_{1}$; PLC: Phospholipase C; RP: Reverse phase; RSM: Response surface methodology; RT: Retention time; TE: Transesterification; UPLC: Ultra-performance liquid chromatography.
Competing interests

The authors declare that they have no competing interests.

\section{Authors' contributions}

SC participated in the design of the study, carried out the experiments, organized and interpreted the data, and drafted the manuscript. RFH performed the ICP-OES and UPLC/MS/MS analysis, and contributed to the manuscript draft. PD contributed to critical discussion, and revised and corrected the manuscript. PMN coordinated the project and the design of the study, critically interpreted the data, and revised the manuscript. All authors read and approved the final manuscript.

\section{Acknowledgments}

The authors thank Novozymes A/S (Denmark) for kindly providing the enzymes and research facilities. This work was financed by the Scientific and Technological Research Council (MINECO, Spain), grant CTQ2010-21183-C02-02/PPQ, by the IV Pla de Recerca de Catalunya, grant 2009SGR-819, by PCI-AECID project A203563511, and by the Generalitat de Catalunya to the 'Xarxa de Referència en Biotecnologia' (XRB). SC acknowledges a doctoral fellowship from the Spanish Ministry of Science and Education (AP2008-04579).

\section{Author details}

'Department of Microbiology, University of Barcelona, Avenida Diagonal 643, Barcelona 08028, Spain. ${ }^{2}$ Department of Analytical Development, Novozymes A/S, Hallas Alle 1, Kalundborg 4400, Denmark. ${ }^{3}$ Department of Bioenergy Opportunities, Novozymes A/S, Krogshoejvej 36, Bagsvaerd 2880, Denmark.

Received: 23 October 2013 Accepted: 10 February 2014

Published: 26 February 2014

\section{References}

1. Dizge N, Aydiner C, Imer DY, Bayramoglu M, Tanriseven A, Keskinlera B. Biodiesel production from sunflower, soybean, and waste cooking oils by transesterification using lipase immobilized onto a novel microporous polymer. Bioresour Technol 2009, 100(6):1983-1991.

2. Fjerbaek $L$, Christensen KV, Norddahl B: A review of the current state of biodiesel production using enzymatic transesterification. Biotechnol Bioeng 2009, 102(5):1298-1315.

3. Ghaly AE, Dave D, Brooks MS, Budge S: Production of biodiesel by enzymatic transesterification: review. Am J Biochem Biotechnol 2010, 6(2):54-76.

4. Kaieda M, Samukawa T, Matsumoto T, Ban K, Kondo A, Shimada Y, Noda H, Nomoto F, Ohtsuka K, Izumoto E, Fukuda H: Biodiesel fuel production from plant oil catalyzed by Rhizopus oryzae lipase in a water-containing system without an organic solvent. J Biosci Bioeng 1999, 88(6):627-631.

5. Kawakami K, Oda Y, Takahashi R: Application of a Burkholderia cepacia lipase-immobilized silica monolith to batch and continuous biodiesel production with a stoichiometric mixture of methanol and crude Jatropha oil. Biotechnol Biofuels 2011, 4(1):42.

6. Watanabe $Y$, Shimada $Y$, Sugihara A, Tominaga Y: Conversion of degummed soybean oil to biodiesel fuel with immobilized Candida antarctica lipase. J Mol Catal B Enzym 2002, 17(3-5):151-155.

7. Robles-Medina A, González-Moreno PA, Esteban-Cerdán L, Molina-Grima E: Biocatalysis: towards ever greener biodiesel production. Biotechnol Adv 2009, 27(4):398.

8. Xu Y, Nordblad M, Nielsen PM, Brask J, Woodley JM: In situ visualization and effect of glycerol in lipase-catalyzed ethanolysis of rapeseed oil. J Molec Catal B 2011, 72(3-4):213-219.

9. Chen X, Du W, Liu D, Ding F: Lipase-mediated methanolysis of soybean oils for biodiesel production. J Chem Technol Biotechnol 2008, 83(1):71-76.

10. Lv D, Du W, Zhang G, Liu D: Mechanism study on NS81006-mediated methanolysis of triglyceride in oil/water biphasic system for biodiesel production. Process Biochem 2010, 45(4):446-450.

11. Cesarini S, Diaz P, Nielsen PM: Exploring a new, soluble lipase for FAMEs production in water-containing systems using crude soybean oil as a feedstock. Process Biochem 2013, 48(3):484-487.

12. Tufvesson P, Lima-Ramos J, Nordblad M, Woodley JM: Guidelines and cost analysis for catalyst production in biocatalytic processes. Org Process Res Dev 2010, 15(1):266-274.

13. Nielsen PM, Brask J, Fjerbaek L: Enzymatic biodiesel production: technical and economical considerations. Eur J Lipid Sci Technol 2008, 110(8):692-700. 
14. Nielsen PM: Proceedings of the 104th AOCS Annual Meeting and Expo: April 28-May 1. Montréal, QC; 2013.

15. Hama S, Kondo A: Enzymatic biodiesel production: an overview of potential feedstocks and process development. Bioresour Technol 2013, 135:386-395.

16. Haas M, McAloon A, Yee W, Foglia T: A process model to estimate biodiesel production costs. Bioresour Technol 2006, 97(4):671-678.

17. Encinar JM, Sanchez N, Martinez G, Garcia L: Study of biodiesel production from animal fats with high free fatty acid content. Bioresour Technol 2011, 102(23):10907-10914.

18. Cowan D, Nielsen PM: Enzymatic Degumming Of Edible Oils And Fats. In Bleaching and Purifying Fats and Oils: Theory and Practice. Edited by Patterson HBW. Urbana, L: AOCS Press; 2009:216-235.

19. Aalrust E, Beyer W, Ottofrickenstein H, Penk G, Plainer H, Reiner R: Enzymatic Treatment of Edible Oils. US Patent: 5,264,367; 1993.

20. Dijstra A: Proceedings of the World Conference on Oilseed Technology and Utilization. Champaign, IL: American Oil Chemists' Society; 1993.

21. van Nieuwenhuyzen W, Tomás MC: Update on vegetable lecithin and phospholipid technologies. Eur J Lipid Sci Technol 2008, 110(5):472-486.

22. Clausen K: Enzymatic oil-degumming by a novel microbial phospholipase. Eur J Lipid Sci Technol 2001, 103(6):333-340.

23. Holm HC, Nielsen PM, Christensen MW: Production of Fatty Acid Alkyl Esters. US Patent: US 2008/0199924 A1; 2008.

24. Dayton CLG, Galhardo F: Enzymatic Degumming Utilizing a Mixture of PLA and PLC Phospholipases. US Patent: US 2008/0182322 A1; 2008

25. Pinisetty D, Moldovan D, Devireddy R: The effect of methanol on lipid bilayers: an atomistic investigation. Ann Biomed Eng 2006, 34(9):1442-1451.

26. Daicheng L, Fucui M: Soybean Phospholipids. In Recent Trends for Enhancing the Diversity and Quality of Soybean Products, Volume 22. Edited by Krezhova D. Rijeka: InTech; 2011.

27. Hitchman T: Purifine ${ }^{\circledast}$ PLC: industrial application in oil degumming and refining. Oil Mill Gazetteer 2009, 115:2-4.

doi:10.1186/1754-6834-7-29

Cite this article as: Cesarini et al: Combining phospholipases and a liquid lipase for one-step biodiesel production using crude oils. Biotechnology for Biofuels 2014 7:29

\section{Submit your next manuscript to BioMed Central and take full advantage of:}

- Convenient online submission

- Thorough peer review

- No space constraints or color figure charges

- Immediate publication on acceptance

- Inclusion in PubMed, CAS, Scopus and Google Scholar

- Research which is freely available for redistribution 